\title{
PENERAPAN MODEL UTAUT UNTUK MEMAHAMI PENERIMAAN DAN PENGGUNAAN LEARNING MANAGEMENT SYSTEM STUDI KASUS: EXPERENTIAL E-LEARNING OF SANATA DHARMA UNIVERSITY
}

\author{
I Gusti Nyoman Sedana dan St. Wisnu Wijaya
}

Program Studi Teknik Informatika, Universitas Sanata Dharma, Mrican, Tromol Pos 29, Yogyakarta, 55002 , Indonesia

E-mail: pandji_jaya@yahoo.com

\begin{abstract}
Abstrak
Experiential E-Learning of Sanata Dharma University (Exelsa) adalah sebuah Learning Management System (LMS) berbasis web yang dikembangkan oleh Universitas Sanata Dharma untuk meningkatkan efektivitas dan kualitas pembelajaran. Exelsa memiliki sejumlah fasilitas seperti tugas online, tes online, bahan kuliah, chating, menjawab kuesioner, melihat pengumuman, forum mata kuliah, kalender kegiatan, dan sebagainya. Makalah ini menjelaskan tentang hasil penelitian mengenai hubungan faktor-faktor yang mempengaruhi penerimaan dan penggunaan Exelsa dengan menggunakan Unified Theory of Acceptance and Use of Technology (UTAUT). Data dikumpulkan dari responden (mahasiswa) yang menggunakan Exelsa melalui pengambilan data dari basis data dan penyebaran kuesioner sejumlah 281 buah. Hasil analisis deskriptif memperlihatkan bahwa sebagian besar responden memiliki tingkat performance expectancy, effort expectancy, social influence, facilitating conditions, dan use behavior yang tergolong tinggi, sementara tingkat behavioral intention sebagian besar responden tergolong sedang. Hasil pengujian dengan korelasi Spearman menunjukkan bahwa performance expectancy, effort expectancy, social influence, dan facilitating condition masing-masing memiliki korelasi positif dan signifikan $(p$-value $<0.01)$ terhadap behavioral intention. Begitu pula behavioral intention memiliki korelasi yang positif dan signifikan dengan use behavior ( $p$-value $<0.05)$. Sementara facilitating condition tidak memiliki korelasi yang signifikan dengan use behavior.
\end{abstract}

Kata Kunci: learning management system, exelsa, UTAUT, korelasi spearman

\begin{abstract}
Experiential E-Learning of Sanata Dharma University (Exelsa) is a web-based Learning Management System (LMS), developed by the University of Sanata Dharma to improve the effectiveness and quality of learning. Exelsa has a number of facilities such as online job, online tests, lectures, chat, answering questionnaires, see the announcement, the course forum, calendar of events, and so forth. This paper describes the results of research on the relationship of the factors that influence the acceptance and use of Exelsa using a Unified Theory of Acceptance and Use of Technology (UTAUT). Data were collected from the respondents (students) who use Exelsa through data retrieval from data bases and the deployment of some 281 pieces of questionnaire. The results of descriptive analysis showed that most respondents have a level of performance expectancy, effort expectancy, social influence, facilitating conditions, and use behavior is high, while the level of behavioral intention majority of respondents classified as moderate. Spearman correlation test results indicate that performance expectancy, effort expectancy, social influence and facilitating condition each have positive and significant correlation ( $\mathrm{p}$-value $<0.01$ ) on behavioral intention. Similarly, behavioral intention has a positive and significant correlation with the use behavior (p-value <0.05). While facilitating condition has no significant correlation with the use behavior.
\end{abstract}

Keywords: learning management system, exelsa, UTAUT, spearman corellation

\section{Pendahuluan}

Deskripsi dasar dari Learning Management System (LMS) adalah sebuah aplikasi perangkat lunak yang mengotomasi administrasi, dokumentasi, pelacakan, dan pelaporan kegiatan- kegiatan pelatihan [1]. Mengimplementasikan LMS adalah sebuah tindakan strategis untuk meningkatkan proses pembelajaran dan interaksi antara mahasiswa dan dosen di perguruan tinggi. LMS berfungsi sebagai alat untuk mendukung manajemen pembelajaran dan membuat interaksi 
antara mahasiswa dan dosen menjadi lebih mudah. Dengan menggunakan LMS mahasiswa dan dosen dapat berinteraksi satu sama lain kapan saja dan di mana saja [2].

Untuk meraih tujuan tersebut, Universitas Sanata Dharma telah memanfaatkan Experiential E-Learning of Sanata Dharma University (Exelsa) sejak tahun 2008. Pengembangan perangkat lunak ini didanai dari program hibah kompetisi Teknologi Informasi dan Komunikasi (TIK) pada tahun 2006 dan dikelola oleh Lembaga Penjaminan Mutu Universitas Sanata Dharma. Pemanfaatan Exelsa diikuti oleh kebijakan dari pihak Universitas untuk mendukung penggunaan Exelsa didalam kelas tradisional (belum menggunakan Exelsa) termasuk pelatihan penggunaan Exelsa, dan pengembangan materi pembelajaran digital untuk seluruh dosen [2].

Hampir selama dua tahun pemanfaatan Exelsa, Universitas Sanata Dharma masih mengalami banyak hambatan untuk mengkombinasikan pembelajaran tradisional dengan Exelsa. Beberapa dosen mengalami kesulitan-kesulitan untuk mengubah cara mereka mengajar dari pengajaran tradisional menjadi kombinasi pengajaran tradisional dengan Exelsa. Disisi lain, berdasarkan wawancara singkat, banyak mahasiswa tidak menggunakan Exelsa dikarenakan berbagai alasan yang terkait dengan niat mereka.

Tujuan penelitian adalah untuk memperoleh pemahaman yang lebih baik terhadap penerimaan dan penggunaan LMS (Exelsa) oleh mahasiswa Universitas Sanata Dharma. Peneliti menggunakan Unified Theory of Acceptance and Use of The Technology (UTAUT), yang dikembangkan oleh Venkatesh, dkk. [3]. Teori ini menyediakan alat yang berguna bagi para manajer yang perlu menilai kemungkinan keberhasilan pengenalan teknologi baru dan membantu mereka memahami penggerak penerimaan dengan tujuan untuk proaktif mendesain intervensi (termasuk pelatihan, sosialisasi, dan lain- lain.) yang ditargetkan pada populasi pengguna yang mungkin cenderung kurang untuk mengadopsi dan menggunakan sistem baru [4]. UTAUT telah diterapkan di lingkungan akademik oleh banyak peneliti. Dasgupta, dkk. [5] menerapkan UTAUT untuk memahami persepsi mahasiswa terhadap penerimaan dan penggunaan case tools. Hasilnya effort expectancy tidak berpengaruh terhadap behavioral intention. Sedangkan facilitating conditions memiliki pengaruh yang signifikan terhadap behavioral intention. Marchewka, dkk. [6] juga melaporkan adanya sedikit perbedaan dengan teori UTAUT ketika mereka menguji UTAUT di lingkungan akademik. Meskipun hasil penelitian-penelitian dengan UTAUT di lingkungan akademik sedikit berbeda dengan model aslinya (di lingkungan non akademik), UTAUT masih memberikan konstribusi untuk memperoleh pemahaman yang lebih baik terhadap penerimaan dan penggunaan TIK di lingkungan akademik. Peneliti percaya dengan menerapkan UTAUT akan membantu peneliti untuk memahami penerimaan dan penggunaan Exelsa. Namun untuk menyesuaikan dengan situasi dan kondisi lingkungan penelitian, dalam penelitian ini peneliti tidak menggunakan variabel moderator.

Experiential E-Learning of Sanata Dharma University (Exelsa) merupakan sebuah Learning Management System (LMS) berbasis web yang diharapkan dapat meningkatkan kualitas pembelajaran dan pendidikan di Universitas Sanata Dharma. Exelsa menyediakan sejumlah fasilitas pembelajaran seperti tugas online, tes online, bahan kuliah, chating, menjawab kuesioner, melihat pengumuman, forum mata kuliah, kalender kegiatan, dan sebagainya. Exelsa juga diharapkan dapat meningkatkan efektivitas dan kualitas komunikasi pembelajaran dengan pendekatan knowledge management diantara berbagai pihak seperti dosen, mahasiswa, program studi, biro administrasi akademik, penyedia media pembelajaran serta berbagai pihak lainnya yang berkepentingan [4].

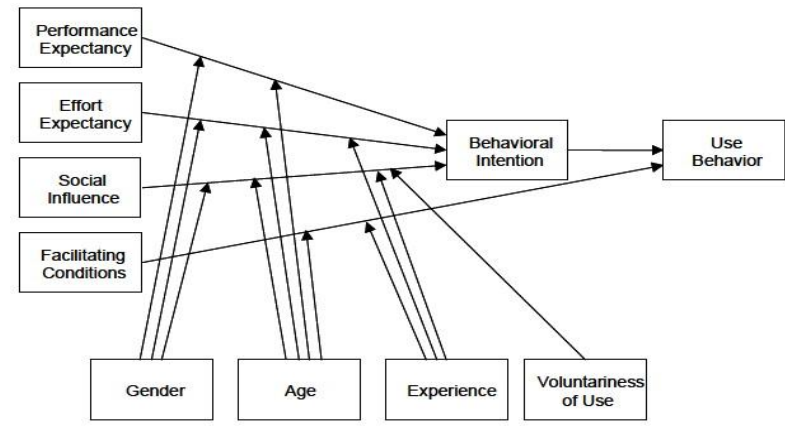

Gambar 1. Model UTAUT [7]. 
UTAUT merupakan salah satu model penerimaan teknologi terkini yang dikembangkan oleh Venkatesh, dkk. [7]. UTAUT menggabungkan fitur-fitur yang berhasil dari delapan teori penerimaan teknologi terkemuka menjadi satu teori. Kedelapan teori terkemuka yang disatukan di dalam UTAUT adalah theory of reasoned action (TRA), technology acceptance model (TAM), motivational model (MM), theory of planned behavior (TPB), combined TAM and $T P B$, model of PC utilization (MPTU), innovation diffusion theory (IDT), dan social cognitive theory (SCT). UTAUT terbukti lebih berhasil dibandingkan kedelapan teori yang lain dalam menjelaskan hingga 70 persen varian pengguna [7].

Setelah mengevaluasi kedelapan model, Venkatesh, dkk. [7] menemukan tujuh konstruk yang tampak menjadi determinan langsung yang signifikan terhadap behavioral intention atau use behavior dalam satu atau lebih di masing-masing model. Konstruk-konstruk tersebut adalah performance expectancy, effort expectancy, social influence, facilitating conditions, attitude toward using technology, dan self-efficacy. Setelah melalui pengujian lebih lanjut, mereka menemukan empat konstruk utama yang memainkan peran penting sebagai determinan langsung dari behavioral intention dan use behavior yaitu, performance expectancy, effort expectancy, social influence, dan facilitating conditions. Sedangkan yang lain tidak signifikan sebagai determinan langsung dari behavioral intention. Disamping itu terdapat pula empat moderator: gender, age, voluntariness, dan experience yang diposisikan untuk memoderasi dampak dari empat konstruk utama pada behavioral intention dan use behavior. Gambar 1 menampilkan keterkaitan antara determinandeterminan dan moderator-moderator ini.

\section{Metodologi}

Penelitian ini menggunakan model UTAUT yang lebih sederhana. Model asli UTAUT dimodifikasi sedemikian rupa hingga menjadi lebih sederhana seperti terlihat pada gambar 2 .

Data yang digunakan dalam penelitian ini adalah data primer dan data sekunder. Data primer adalah data yang diperoleh langsung di lapangan. Sedangkan data sekunder adalah data yang diperoleh dari sumber-sumber yang telah ada [8]. Teknik pengambilan data dalam penelitian ini adalah survei dan basis data. Metode pengambilan sampelnya menggunakan metode purposive sampling dengan kriteria: 1) kelas kuliah yang dipilih adalah kelas yang memanfaatkan Exelsa untuk keperluan pembelajaran, 2) responden merupakan mahasiswa yang mengikuti kuliah yang telah ditentukan pada saat penelitian, dan 3) responden merupakan pengguna Exelsa. Melalui survei akan diperoleh data primer, sedangkan data sekunder akan diperoleh dari pengambilan data perilaku pengguna melalui basis data. Responden dalam penelitian ini adalah mahasiswa Universitas Sanata Dharma yang menggunakan Exelsa.

Semua skala, kecuali use behavior, dinilai menggunakan skala Likert 5 poin, yaitu: 1) Sangat Tidak Setuju, 2) Tidak Setuju, 3) Netral, 4) Setuju, dan 5) Sangat Setuju. Instrumen dalam penelitian ini (skala UTAUT) dikembangkan dari instrumen penelitian Venkatesh, dkk. [7] yang disesuaikan dengan konteks penelitian di Universitas Sanata Dharma. Skala ini mencakup lima aspek yaitu performance expectancy (PE), effort expectancy (EE), social influence (SI), facilitating conditions (FC), dan behavioral intention (BI). Sedangkan data yang digunakan untuk mengukur use behavior berasal dari pembobotan frekuensi penggunaan Exelsa dalam waktu 5 minggu. Frekuensi penggunaan Exelsa diperoleh dengan pengambilan data yang ada di basis data.

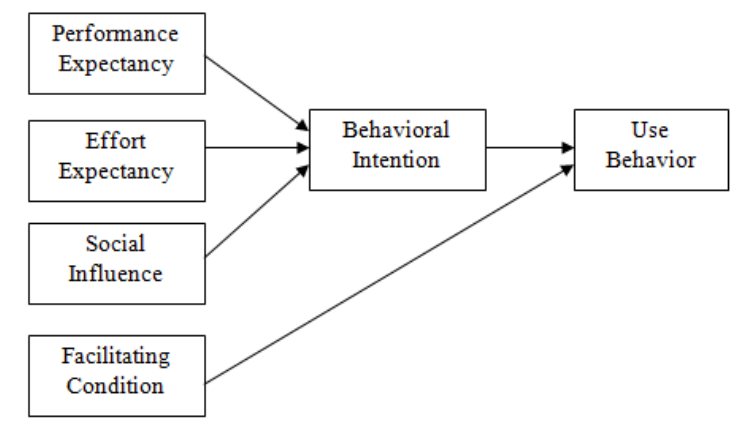

Gambar 2. Model penelitian[5]. 
Sebanyak 281 kuesioner disebarkan di dalam kelas untuk mengurangi peluang terjadinya ketidakvalidan dalam mengisi kuesioner. Kuesioner ini disebarkan dalam 2 tahap. Tahap pertama (pre-test) disebarkan kuesioner sebanyak 59 buah. Tahap pertama bertujuan memperoleh data yang digunakan untuk menguji validitas dan reliabilitas instrumen penelitian. Uji validitas bertujuan menguji apakah setiap item pertanyaan telah valid dalam mencerminkan atribut yang hendak diukur [9]. Item yang memiliki korelasi item-total $<0.3$ disebut belum memenuhi persyaratan dan dinyatakan tidak valid [10][11]. Hasil uji validitas skala penelitian tidak ditampilkan di sini. Setelah uji validitas, kemudian dilanjutkan dengan uji reliabilitas. Ide pokok yang terkandung di dalam konsep reliabilitas adalah sejauhmana hasil suatu pengukuran dapat dipercaya [9].

Pengujian reliabilitas dilakukan dengan menggunakan item-item yang valid dengan melihat perolehan Alpha $(\alpha)$ Cronbach dari masing-masing skala. Tabel 1 menyajikan hasil pengujian reliabilitas. Dari tabel I dapat diketahui bahwa semua skala memiliki tingkat reliabilitas alpha > 0.70. Menurut Nunnaly [12] dapat disimpulkan bahwa keseluruhan skala penelitian adalah reliabel. Setelah memenuhi persyaratan uji validitas dan reliabilitas, instrumen penelitian ini dinilai telah layak sebagai alat pengumpul data penelitian yang sesungguhnya. Tabel I diperoleh dari data pre-test penelitian.

Setelah melakukan pengujian validitas dan reliabilitas, 222 kuesioner disebarkan pada tahap berikutnya. Hasilnya, 204 buah kuesioner dinyatakan layak untuk dianalisis sedangkan sisanya tidak layak karena ada pernyataan yang tidak diisi. Dari 204 responden, 107 orang adalah laki-laki, sedangkan sisanya adalah perempuan. Karakteristik responden penelitian selengkapnya dapat dilihat pada tabel II dan tabel III. Tabel II dan tabel III diperoleh dari data primer yang telah diolah.

TABEL I

Hasil Reliabilitas AlPHa CRONBACH

\begin{tabular}{ccc}
\hline \hline Skala Penelitian & Alpha Reliabilitas & Keterangan \\
\hline PE & 0.815 & Reliabel \\
EE & 0.738 & Reliabel \\
SI & 0.716 & Reliabel \\
FC & 0.780 & Reliabel \\
BI & 0.891 & Reliabel \\
\hline \hline
\end{tabular}

TABELII

KARAKTERISTIK JENIS KELAMIN

\begin{tabular}{|c|c|c|c|}
\hline No. & Jenis Kelamin & Jumlah & Persentase \\
\hline 1. & Laki-Laki & 107 & $52.45 \%$ \\
\hline \multirow[t]{2}{*}{2.} & Perempuan & 97 & $47.55 \%$ \\
\hline & Total & 204 & $100 \%$ \\
\hline \multicolumn{4}{|c|}{$\begin{array}{c}\text { TABELIII } \\
\text { KARAKTERISTIK PROGRAM STUDI } \\
\end{array}$} \\
\hline No & Program Studi & Jumlah & Persentase \\
\hline 1 & Teknik Informatika & 72 & $35.29 \%$ \\
\hline 2 & Teknik Mesin & 49 & $24.02 \%$ \\
\hline 3 & Teknik Elektro & 20 & $9.80 \%$ \\
\hline 4 & Pendidikan Akuntansi & 35 & $17.16 \%$ \\
\hline \multirow[t]{2}{*}{5} & Bimbingan Konseling & 28 & $13.73 \%$ \\
\hline & Total & 204 & $100 \%$ \\
\hline
\end{tabular}




\section{Hasil dan Pembahasan}

Analisis Deskriptif: Standar skor rata-rata diperoleh dalam masing-masing skala (skor teoritik) dan data penelitian menerangkan skor sebenarnya yang diperoleh subyek dalam mengerjakan tes (skor empirik). Skor teoritik dan empirik masing-masing skala penelitian tersaji dalam tabel IV yang diperoleh dari data primer yang telah diolah dan tabel $\mathrm{V}$ yang diperoleh dari data primer dan sekunder yang telah diolah. Berdasarkan data dari tabel IV dan V, selanjutnya subyek akan dikategorikan guna memberi interpretasi terhadap skor skala dengan cara, menguji signifikansi perbedaan mean skor empirik dan mean skor teoritis. Cara ini bertujuan untuk mengkategorikan individu ke dalam kategori rendah, sedang, dan tinggi namun tidak mengasumsikan bahwa skor subyek dalam populasinya terdistribusi secara normal [10]. Untuk menggunakan cara ini, terlebih dahulu akan ditetapkan suatu interval batas bawah dan batas atas skor-skor yang berbeda secara signifikan dari harga mean teoritis, menurut tingkat kepercayaan yang diinginkan (dalam penelitian ini tingkat kepercayaannya $99 \%$ atau taraf signifikansi $\alpha=0,1)$ [10]. Berikut rumusan intervalnya:

$$
\mu-\mathrm{t}_{(\alpha / 2, \mathrm{n}-1)}(\mathrm{SD} / \sqrt{ } \mathrm{n}) \leq \mathrm{X} \leq \mu+\mathrm{t}_{(\alpha / 2, \mathrm{n}-1)}\left(\mathrm{SD} / \bigvee_{\mathrm{n}}\right)
$$
di mana:

$$
\begin{array}{ll}
\mu & : \text { Mean teoritik skala } \\
\mathrm{t}(\alpha / 2, \mathrm{n}-1) & : \text { Harga kritis t pada taraf signifikansi } \\
& \alpha / 2 \text { dan derajat kebebasan } \mathrm{n}-1 \\
\mathrm{SD} & : \text { Standar deviasi skor empirik } \\
\mathrm{n} & : \text { Jumlah responden. }
\end{array}
$$

Interval ini merupakan interval skor yang digolongkan sebagai kategori sedang pada taraf signifikansi sebesar $\alpha$. Skor yang lebih besar dari batas atas interval akan diinterpretasikan sebagai tinggi sedangkan skor-skor yang lebih kecil dari batas bawah interval dikategorikan sebagai rendah [10]. Berdasarkan rumusan interval ini, maka diperoleh hasil kategori seperti yang disajikan dalam tabel VI yang diperoleh dari data primer dan data sekunder yang telah diolah.
Tabel VI menunjukkan bahwa sebagian besar responden memiliki tingkat performance expectancy (PE), effort expectancy (EE), social influence (SI), facilitating conditions (FC), dan use behavior (USE) yang tinggi. Secara berturutturut persentasenya adalah 79\%, 73\%, 52\%, 54\%, dan $41 \%$. Sementara tingkat behavioral intention (BI) sebagian besar responden, masuk dalam kategori sedang (persentasenya 43\%). Tabel VII diperoleh dari data primer dan sekunder yang telah diolah.

Tingginya tingkat performance expectancy menyatakan sebagian besar responden menganggap penggunaan Exelsa akan membantunya untuk mendapatkan keuntungankeuntungan kinerja di pekerjaannya seperti, lebih mudah dan cepat dalam mengerjakan dan menyelesaikan tugas-tugas kuliah. Sebagian besar responden juga merasa bahwa tidak diperlukan usaha yang keras untuk menggunakan Exelsa. Ini ditunjukkan dari tingginya tingkat effort expectancy yang diperoleh sebagian besar responden. Orang-orang yang dianggap penting oleh responden juga memberikan pengaruh terhadap penggunaan Exelsa. Hal ini dilihat dari tingginya tingkat social influence. Tingginya tingkat facilitating conditions menunjukkan kepercayaan yang tinggi dari sebagian besar responden terhadap ketersediaan infrastruktur teknik dan organisasional untuk mendukung penggunaan Exelsa. Frekuensi penggunaan Exelsa dalam 5 minggu menunjukkan bahwa sebagian besar responden memiliki tingkat use behavior yang tergolong tinggi. Hal ini dapat disebabkan karena waktu 5 pekan yang diambil untuk mengukur frekuensi penggunaan Exelsa adalah masa di mana mahasiswa akan dan sedang menempuh ujian tengah semester. Kecenderungannya, pada masa-masa ini mahasiswa akan semakin disibukkan dengan tugas-tugas kuliah dan sibuk menyiapkan bahan ujian termasuk men-download materi digital. Sehingga hal ini akan meningkatkan frekuensi penggunaan Exelsa. Sementara, persentase sebagian besar responden yang masuk kategori

\begin{tabular}{|c|c|c|c|c|c|c|}
\hline & \multicolumn{2}{|c|}{ PE } & \multicolumn{2}{|c|}{$\overline{\mathrm{EE}}$} & \multicolumn{2}{|c|}{ SI } \\
\hline & Teoritik & Empirik & Teoritik & Empirik & Teoritik & Empirik \\
\hline Skor Min & 4 & 5 & 4 & 5 & 4 & 5 \\
\hline Skor Max & 20 & 20 & 20 & 20 & 20 & 18 \\
\hline SD & 2.667 & 2.531 & 2.667 & 2.581 & 2.667 & 2.18 \\
\hline
\end{tabular}
sedang (43\%) untuk tingkat behavioral intention, hanya terpaut $1 \%$ dari jumlah responden yang masuk dalam kategori tinggi (42\%).

TABEL IV

PERBANDINGAN DATA TEORITIK DAN EMPIRIK 
TABEL V

PERBANDINGAN DATA TEORITIK DAN EMPIRIK (LANJUTAN)

\begin{tabular}{lllllll}
\hline \hline & \multicolumn{3}{l}{ FC } & BI & \multicolumn{2}{c}{ USE } \\
\hline \multirow{3}{*}{ Skor Min } & Teoritik & Empirik & Teoritik & Empirik & Teoritik & Empirik \\
Skor Max & 4 & 7 & 3 & 3 & 1 & 1 \\
Mean & 20 & 20 & 15 & 15 & 5 & 5 \\
SD & 12 & 12.529 & 9 & 9.549 & 3 & 3.123 \\
\hline \hline
\end{tabular}

TABEL VI

KATEGORI SKOR INSTRUMEN PENELITIAN

\begin{tabular}{crlll}
\hline \hline Skala & \multicolumn{2}{c}{ Interval } & \multicolumn{2}{c}{ Kategori } \\
\hline PE & $11 \leq \mathrm{x} \leq 12$ & $15(7 \%)$ & $27(13 \%)$ & $162(79 \%)$ \\
EE & $11 \leq \mathrm{x} \leq 12$ & $23(11 \%)$ & $33(16 \%)$ & $148(73 \%)$ \\
SI & $11 \leq \mathrm{x} \leq 12$ & $32(16 \%)$ & $66(32 \%)$ & $106(52 \%)$ \\
FC & $11 \leq \mathrm{x} \leq 12$ & $30(15 \%)$ & $64(31 \%)$ & $110(54 \%)$ \\
BI & $8 \leq \mathrm{x} \leq 9$ & $30(15 \%)$ & $88(43 \%)$ & $86(42 \%)$ \\
USE & $2 \leq \mathrm{x} \leq 3$ & $40(20 \%)$ & $80(39 \%)$ & $84(41 \%)$ \\
\hline \hline
\end{tabular}

TABEL VII

KORELASI SPEARMAN

\begin{tabular}{llllllll}
\hline \hline & & PE & EE & SI & FC & BI & USE \\
\hline PE & Koefesien Korelasi & 1.000 & $.342^{* *}$ & $.245^{* *}$ & $.422^{* *}$ & $.304^{* *}$ & $.042^{* *}$ \\
& Sig. (1- tailed) &. & .000 & .000 & .000 & .000 & .276 \\
EE & Koefesien Korelasi & $.342^{* *}$ & 1.000 & .051 & $.433^{* *}$ & $.346^{* *}$ & .111 \\
& Sig. (1- tailed) & .000 &. & .236 & .000 & .000 & .056 \\
SI & Koefesien Korelasi & $.245^{* *}$ & .051 & 1.000 & $.204 * *$ & $.187^{* *}$ & -.045 \\
& Sig. (1- tailed) & .000 & .236 &. & .002 & .004 & .260 \\
FC & Koefesien Korelasi & $.422^{* *}$ & $.443^{* *}$ & $.204^{* *}$ & 1.000 & $.382^{* *}$ & .053 \\
& Sig. (1- tailed) & .000 & .000 & .002 &. & .000 & .226 \\
BI & Koefesien Korelasi & $.304^{* *}$ & $.346^{* *}$ & $.187^{* *}$ & $.382^{* *}$ & 1.000 & $.161^{*}$ \\
& Sig. (1- tailed) & .000 & .000 & .004 & .000 &. & .011 \\
\multirow{2}{*}{ USE } & Koefesien Korelasi & $.042^{* *}$ & .111 & -.045 & .053 & $.161^{*}$ & .011 \\
& Sig. (1- tailed) & .276 & .056 & 260 & .226 & .011 & 1.000 \\
\hline \hline
\end{tabular}

Korelasi Bivariate: Penelitian ini akan menguji hubungan masing masing variabel secara terpisah dengan menggunakan uji statistik korelasi bivariate one tailed. Uji one-tailed dilakukan dengan asumsi bahwa hipotesis pada penelitian ini sudah diketahui arahnya [11]. Teknik ini dipilih untuk memberikan gambaran hubungan masing-masing variabel sebagaimana digambarkan dalam model. Walaupun teknik ini belum menghasilkan nilai pengaruh secara simultan antara variabel independent dan dependent. Hasil pengujian korelasi Spearman disajikan dalam tabel VII.

Dari tabel VII dapat diketahui bahwa performance expectancy (PE) memiliki korelasi positif dan signifikan $(p$-value $<0.01)$ terhadap behavioral intention (BI). Hasil ini dapat disebabkan oleh keuntungan-keuntungan yang dapat diperoleh responden jika menggunakan
Exelsa, terutama dalam menyelesaikan tugastugas kuliah. Keuntungan ini ternyata memiliki hubungan dengan niat responden dalam menggunakan Exelsa. Kemudahan penggunaan Exelsa juga menunjukkan adanya hubungan dengan niat untuk menggunakannya, terlihat dari korelasi positif dan signifikan ( $p$-value $<0.01)$ effort expectancy (EE) terhadap behavioral intention (BI). Social influence (SI) juga memiliki korelasi positif dan signifikan ( $p$-value $<0.01)$ terhadap behavioral intention (BI). Namun facilitating condition ternyata tidak memiliki korelasi yang signifikan dengan use behavior(USE).

Hasil pengujian juga menunjukkan adanya korelasi positif dan signifikan antara facilitating condition dengan behavioral intention. Temuan ini berbeda dari yang dilaporkan oleh Venkatesh, dkk. namun sependapat dengan temuan yang 
dilaporkan oleh Dasgupta, dkk. [5]. Hal ini mungkin disebabkan oleh perbedaan lingkungan di mana penelitian ini diadakan.

Tabel VII juga menunjukkan bahwa niat untuk menggunakan Exelsa memiliki hubungan dengan penggunaannya. Hal ini dapat dilihat dari korelasi yang positif dan signifikan antara behavioral intention dengan use behavior $(\mathrm{r}=0.161 ; \mathrm{p}$-value $<0.05)$. Temuan ini sesuai dengan konsep dasar dari model-model penerimaan pengguna yaitu, niat untuk menggunakan teknologi informasi akan mempengaruhi penggunaan sebenarnya teknologi informasi tersebut [7].

\section{Kesimpulan}

Hasil penelitian menunjukkan bahwa UTAUT adalah alat yang berguna untuk menjelaskan penerimaan dan penggunaan Exelsa oleh mahasiswa Universitas Sanata Dharma. Hasil analisis deskriptif memperlihatkan bahwa sebagian besar responden memiliki tingkat performance expectancy, effort expectancy, social influence, facilitating conditions, dan use behavioryang tergolong tinggi, sementara tingkat behavioral intention sebagian besar responden tergolong sedang. Hasil pengujian dengan korelasi Spearman menunjukkan bahwa performance expectancy, effort expectancy, social influence, dan facilitating condition masing-masing memiliki korelasi positif dan signifikan ( $p$ value $<0.01)$ terhadap behavioral intention. Begitu pula behavioral intention memiliki korelasi yang positif dan signifikan dengan use behavior ( $p$ value $<0.05$ ). Sementara facilitating condition tidak memiliki korelasi yang signifikan dengan use behavior.

Penelitian selanjutnya sebaiknya menggunakan responden yang lain, misalnya para dosen. Hal ini untuk memperoleh pemahaman yang lebih baik mengenai persepsi para dosen terhadap penerimaan dan penggunaan Exelsa. Interaksi antara dosen dan mahasiswa adalah kunci untuk memperoleh keberhasilan dalam pengimplementasian Exelsa.

\section{Referensi}

[1] R.K. Ellis, "Field Guide to Learning Management Systems" The American Society for Training \& Development (ASTD), pp. 1-7, 2009.

[2] Tim Penyusun, Rencana Strategis 20082012, Universitas Sanata Dharma, Yogyakarta, 2008.

[3] P.K.G. Tibendarana \& P.J. Ogao, "Information Communication Technologies Acceptance and Use Among University Communities in Uganda: A Model for Hybrid Library Services End-Users," International Journal of Computing and ICT Research, vol. 1, pp. 60-75, 2008.

[4] P3MP, Manual Exelsa Mahasiswa, http://

www.Exelsa.usd.ac.id/goDownload.php ?file=./ uploads/ tutorial/ManualExelsa, retrieved August 25, 2009.

[5] S. Dasgupda, M. Haddad, P. Weiss, E. Bermudez, "User Acceptance of Case Tools in System Analysis and Design: an Empirical Study, "Journal of Informatics Education Research, vol. 9, pp. 51-78, 2007.

[6] J.T. Marchewka, C. Liu, K. Kostiwa, "An Application of the UTAUT Model for Understanding Student Perceptions Using Course Management Software, Communications of the IIMA, vol. 7, 93-104, 2007.

[7] V. Venkatesh, M.G. Morris, G.B. Davis, F.D. Davis, "User acceptance of information technology: toward a unified view, " $M I S$ Quarterly, vol. 27, pp. 425-478, 2003.

[8] M.I. Hasan, Pokok-Pokok Materi Metodologi Penelitian dan Aplikasinya, Ghalia Indonesia, Jakarta, 2002.

[9] S. Azwar, Reliabilitas dan Validitas, 3rd ed., Pustaka Pelajar, Yogyakarta, 2008.

[10] S. Azwar, Penyusunan Skala Psikologi, 1st ed., Pustaka Pelajar, Yogyakarta, 2007.

[11] Sugiyono, Metode Penelitian Kuantitatif, Kualitatif, dan $R \& D$, 6th ed., Alfabeta, Bandung, 2009.

[12] J.C, Nunnally, Psycometric Theory, 2nd ed., Tata McGraw-Hill Publishing Company Limited, New Delhi, 1981. 